\title{
Levantamento etnobotânico de espécies arbóreas no assentamento Tabuleiro Grande, Apodi, Rio Grande do Norte
}

\section{Ethnobotanical survey of tree species in the Tabuleiro Grande settlement, Apodi, Rio Grande do Norte}

\author{
Mônica Costa Cordeiro ${ }^{1}$; Rejane Tavares Botrel ${ }^{2}$; Alan Cauê Holanda ${ }^{3}$
}

\begin{abstract}
Resumo: Objetivou-se realizar um levantamento etnobotânico no Projeto de Assentamento Tabuleiro Grande, localizado em Apodi, Rio Grande do Norte, contribuindo para o resgate do conhecimento popular discutindo as implicações do uso da vegetação arbórea na conservação dos recursos florestais. A condução do estudo foi por meio da observação direta e entrevistas semiestruturadas (21 entrevistas). Para análise dos dados foram feitas abordagens qualitativas (acesso a informações subjetivas) e quantitativas (Valor de Uso; índices de diversidade de Shannon e de equabilidade de Pielou). Foram mencionadas no levantamento 57 espécies arbóreas, entre nativas e exóticas, distribuídas em 26 famílias e enquadradas nas seguintes categorias de uso: Madeira (móveis e construção), Medicina/Higiene, Apicultura, Lenha, Veterinária Popular, Forragem, Alimentação Humana e Outros. Com os resultados obtidos, conclui-se que a comunidade estudada possui conhecimento sobre um grande número de espécies arbóreas. No entanto, no que diz respeito a "uso", poucas espécies são, de fato, utilizadas. De forma geral, o conhecimento popular na comunidade está mantido com uma pequena parcela dos entrevistados e não é repassado, tendendo a tornar-se cada vez mais escasso.
\end{abstract}

Palavras-chave: Conhecimento popular; Recursos florestais; Valor de uso.

\begin{abstract}
The aim this study was to realize ethnobotanical survey in Settlement Tabuleiro Grande Project, located in Apodi $\mathrm{RN}$, to contribute to the rescue of popular knowledge and discuss the implications of the use of trees in the conservation of forest resources. The conduct of the study was through direct observation and semi-structured interviews (21 interviews). Data analysis were made qualitative approaches (access to subjective information) and quantitative (use value -VU, Shannon diversity and Pielou evenness indexes). Were mentioned in the survey 57 tree species native and exotic, distributed in 26 families and classified in the following categories of use: wood (furniture and construction), Medicine / hygiene, Beekeeping, Firewood, Popular Veterinary, Fodder, Food and Others. With the results, it is concluded that the studied community has knowledge of a large number of tree species. However, with regard to "use", few are actually used. In general, the popular knowledge in the community is maintained with a small portion of respondents and is not passed, tending to become increasingly scarce.
\end{abstract}

Key words: Popular knowledge. Forest resources. Use of value.

\footnotetext{
*Autor para correspondência

Recebido para publicação em 14/12/2016; aprovado em 20/02/2016

${ }^{1}$ Graduanda em Engenharia florestal, Centro de Ciências Agrárias, Universidade Federal Rural do Semiárido, monicacosta1203@ gmail.com

${ }^{2}$ Doutora em Ciências Vegetais, Centro de Ciências Agrárias, Universidade Federal Rural do Semiárido, rtbotrel@ufersa.edu.br

${ }^{3}$ Doutor em Ciências Florestais, Centro de Ciências Agrárias, Universidade Federal Rural do Semiárido, alan.holanda@ufersa.edu.br
} 


\section{INTRODUÇÃO}

O Nordeste brasileiro possui diversos ecossistemas, como matas úmidas e secas, manguezais e vegetação costeira, onde se encontram plantas, animais e minerais, oferecendo grande diversidade de produtos para o ser humano (Maia, 2012). A Caatinga, um dos 06 (seis) biomas brasileiros, ocupa grande parte do território nordestino (MAIA, 2012).

Historicamente, a Caatinga sofreu impactos decorrentes do processo de uso e ocupação do solo, que a degradaram paulatinamente (SOUZA, 2006). Essa degradação é influenciada pela predisposição geoambiental e pela ação do homem, pois a ocupação desordenada agravou os impactos Consequentemente, a vegetação da Caatinga passou a ser usada como fonte de energia em domicílios, olarias, casas de farinha, padarias, indústria do gesso, fabricas de cimento e siderúrgicas A pecuária extensiva, o extrativismo insustentável e a agricultura de baixa tecnologia também contribuíram fortemente para esta transformação (SOUZA, 2006).

O estado de devastação no qual a Caatinga se encontra atinge as populações humanas ali existentes. Essas populações possuem conhecimento sobre a vegetação local, repassando-o de geração para geração. Porém, com o avanço do desmatamento e a perda da biodiversidade, esse conhecimento corre sério risco de se perder.

Segundo Maia (2012), a vida do ser humano está intimamente ligada à natureza. $\mathrm{O}$ ser humano faz parte dela, mesmo que não perceba. Assim, tudo o que o homem realiza, ou seja, seus valores e sua cultura refletem não somente no seu bem estar, mas também no bem estar da natureza.

Ferraz et al (2005) afirma que o saber popular contribui para a preservação dos recursos naturais, uma vez que esse conhecimento pode ser utilizado no planejamento de ações, unindo a preservação e as necessidades da população local.

Assim, a etnobotânica, como ciência que estuda as relações entre a vegetação e 0 ser humano (ALBUQUERQUE; HANAZAKI, 2006), se constitui importante ferramenta na valorização e difusão do conhecimento das populações locais. Unir o saber científico e popular pode ser muito valioso para a descoberta de novos fármacos, para a preservação de áreas e para o desenvolvimento econômico e social da região (ALBUQUERQUE; ANDRADE, 2001).

Portanto, objetivou-se realizar levantamento etnobotânico no Projeto de Assentamento Tabuleiro Grande, localizado em Apodi Rio Grande do Norte, contribuindo para o resgate do conhecimento da população local e discutindo as implicações dos usos da vegetação arbórea na conservação dos recursos florestais.

\section{MATERIAL E MÉTODOS}

O estudo foi realizado no Projeto de Assentamento (PA) Tabuleiro Grande, localizado no município de Apodi (RN) (Figura 1). O município de Apodi localiza-se na mesorregião Oeste Potiguar e na microrregião Chapada do Apodi. (MASCARENHAS, 2005). Localizado a $350 \mathrm{~km}$ da capital Natal, Apodi é o município mais populoso da Chapada do Apodi. Porém, apresenta a menor taxa de urbanização da microrregião (SANTANA JÚNIOR, 2010). O relevo é plano com declividade dominante inferior a $02,00 \%$ e o clima é tropical quente de seca acentuada (SANTANA JÚNIOR, 2010).

Figura 1. Localização do estado do Rio Grande do Norte no Brasil e do município de Apodi no estado.

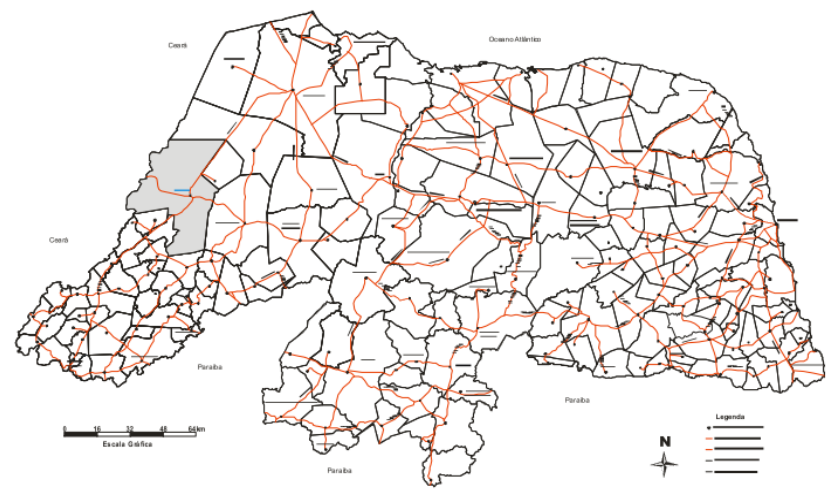

Fonte: Brasil (2005)

O PA Tabuleiro Grande fica a aproximadamente $23 \mathrm{~km}$ da sede de Apodi. No local vivem 45 famílias, que obtêm sua renda da apicultura, ovinocultura e da caprinocultura, principalmente. No Polo Góis, onde está localizado o PA Tabuleiro Grande, há um posto de saúde, duas escolas de ensino fundamental, uma igreja católica e uma igreja evangélica. O assentamento surgiu em 1998, da parceria entre INCRA, Comissão Pastoral da Terra e Sindicato dos trabalhadores. No assentamento são desenvolvidos trabalhos de manejo da caatinga em parceria com universidades.

Antes de se iniciar a coleta de dados, foi realizada uma visita ao PA Tabuleiro Grande, no intuito de esclarecer os objetivos da pesquisa, bem como solicitar a colaboração voluntária a todos os moradores adultos do local, que tivessem conhecimento a respeito da vegetação nativa. Uma vez que o entrevistado aceitasse participar da pesquisa, este era convidado a assinar um Termo de Consentimento Prévio e Esclarecido, permitindo que o entrevistador o visitasse para colher informações e que essas pudessem ser expostas. De posse dos Termos de Consentimento assinados, o entrevistador passou para a próxima etapa da pesquisa onde foram realizadas entrevistas.

A condução dos estudos etnobotânicos foi por meio da observação direta e entrevistas semiestruturadas que permitiram que os entrevistados expressassem suas opiniões a respeito das espécies arbóreas e seus usos (ALENCAR; GOMES, 1988). Durante as entrevistas procurou-se diferenciar uso e conhecimento de espécies arbóreas pela comunidade estudada. Na listagem livre os colaboradores foram solicitados a citar nomes populares de espécies arbóreas conhecidas e, a partir dessa listagem, foram direcionados à entrevista semiestruturada, a fim de obter informações específicas sobre as plantas mencionadas.

Após as entrevistas foram realizadas turnês-guiadas com entrevistados no próprio assentamento, de acordo com sua disponibilidade, para coleta das plantas citadas. O material botânico testemunho, coletado durante as turnês guiadas, foi identificado por meio de consultas à especialistas e literatura específica.

A análise dos dados foi feita por meio de abordagens qualitativas e quantitativas. A abordagem qualitativa teve como interesse acessar informações subjetivas sobre a relação 
entre os seres humanos e o ambiente vegetal. A abordagem quantitativa objetivou conhecer em números dessa relação.

Para análise da concordância quanto ao uso das espécies nativas citadas durante a entrevista foi utilizado o valor de uso (VU) (PHILLIPS; GENTRY, 1993) onde foi calculado para cada espécie e categoria de uso, empregando a Eq. 1:

$$
\mathrm{VU}=\Sigma \mathrm{Ui} / \mathrm{n}
$$

Sendo: VU- valor de uso; Ui - número de usos mencionados por cada informante; $\mathrm{N}$ - número total de informantes.

Foram utilizados também, para análise dos dados, índices de diversidade de Shannon-Wiener (Eqs. 2. e 3) e de equabilidade de Pielou (Eq. 4) (BEGOSSI, 1996, KENT; COKER, 1992).

$$
\begin{aligned}
& \mathrm{H}^{\prime}=-\Sigma \text { pi ln pi } \\
& \mathrm{pi}=\mathrm{ni} / \mathrm{N}
\end{aligned}
$$

Sendo: H'- Índice de diversidade de Shannon-Wiener; ni - $\mathrm{n}^{\mathrm{o}}$ de citações por espécie; $\mathrm{N}$ - $\mathrm{n}^{\mathrm{o}}$ total de citações; ln logaritmo natural.

$$
\text { J' - H'/Hmáx }
$$

Sendo: J' - índice de equabilidade de Pielou; Hmáx - ln do $\mathrm{n}^{\mathrm{o}}$ total de espécies.

Esses índices são utilizados em estudos etnobotânicos para aferir o quanto a diversidade local é usada pela população, sendo a diversidade e a riqueza florística diretamente proporcionais ao número de espécies utilizadas (BEGOSSI, 1996).

Todas as espécies arbóreas, nativas e exóticas, citadas pelos informantes foram incluídas na análise dos dados.

Durante as visitas ao Projeto de Assentamento Tabuleiro Grande foram realizadas 21 entrevistas, entre os meses de setembro e novembro de 2013, com um informante por residência.

\section{RESULTADOS E DISCUSSÃO}

Para o gênero observou-se predominância do feminino com 57\%. A idade dos informantes variou entre 18 e 72 anos, divididos nas seguintes classes (Figura 2).

Figura 2. Distribuição percentual das idades dos informantes residentes no Projeto de Assentamento Tabuleiro Grande, Apodi, Rio Grande do Norte

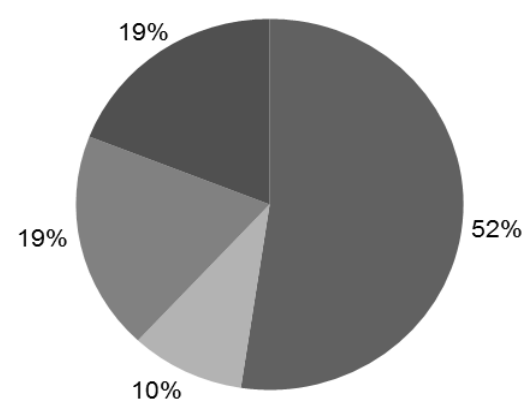

- 18 - 31 anos

$\because 32-45$ anos

$\because 46-59$ anos

- $60-74$ anos
Comumente, as comunidades rurais são compostas por pessoas de idade avançada (SILVA et al., 2012; ALVES; POVH, 2013) uma vez que as pessoas mais jovens acabam saindo da região em busca de trabalho e estudo. No entanto, no PA Tabuleiro Grande esse quadro se apresenta invertido, tendo em vista que a maioria das pessoas nessa faixa etária é composta por donas de casa, que não exercem outra atividade. Além disso, as atividades que conferem renda as famílias são feitas no próprio assentamento ou nas redondezas, garantindo a permanência dos mais jovens localmente.

O tempo de residência dos informantes no assentamento variou de 04 meses a 11 anos. Desta forma, o tempo de residência foi dividido em 05 classes (Figura 3) A categoria "Outros" (10,00\%) refere-se aos casos, com declaração que mora no local a menos de um ano ou não sabe informar.

Figura 3. Distribuição percentual do tempo de residência dos informantes residentes no Projeto de Assentamento Tabuleiro Grande, Apodi, Rio Grande do Norte

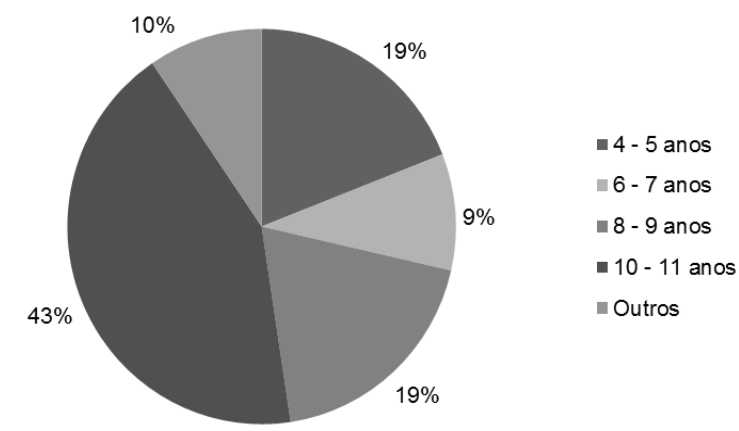

Quanto à procedência, 20 informantes declararam ser de Apodi (RN), e 01 de Luís Gomes (RN). Todos residem em casas de alvenaria e afirmaram serem agricultores. Apenas 03 declararam exercer outras atividades no assentamento, sendo 02 conhecidos como cortadores de lenha, atividade que complementa a renda familiar, e 01 como coletor de sementes, prática que não é feita como fonte de renda.

Foram registradas 57 espécies, das quais 09 não puderam ser identificadas por falta de material vegetativo e/ou reprodutivo por ocasião da coleta. As espécies foram distribuídas em 26 famílias e enquadradas nas categorias Madeira (móveis e construção), Medicina/Higiene, Apicultura, Lenha, Veterinária Popular, Forragem, Alimentação Humana e Outros. Ao comparar o número de espécies do presente trabalho com os números encontrados em levantamentos etnobotânicos em comunidades tradicionais (ALMEIDA, 2011: 86 espécies; LUCENA et al, 2012: 101 espécies; ROQUE; LOIOLA, 2013: 69 espécies), percebe-se que o mesmo é baixo. isso pelo fato de as populações tradicionais manterem uma relação de proximidade com a biodiversidade vegetal favorecida pelo tempo, enquanto que no presente trabalho, os moradores se encontram na região há, no máximo, 11 anos. O índice de diversidade de Shannon-Wiener para o assentamento foi 1,60 nats/ind. Comparando esse índice com os encontrados em outros trabalhos (CUNHA; BORTOLOTTO, 2011: 5,03 nats/ind; FERRAZ et al., 2006: 2,4 nats/ind), percebe-se que o mesmo foi inferior ao encontrado em comunidades rurais.

Verifica-se que a categoria Apicultura foi a atividade mais citada, com 33 espécies $(20,89 \%)$, seguida por 
Medicina/Higiene e Forragem, com 23 espécies (16,46\%) cada, Madeira, com 20 espécies (12,66\%), Alimentação Humana, com 17 espécies (10,76\%), Lenha, com 15 espécies $(09,49 \%)$, Veterinária Popular, com 12 espécies $(06,96 \%)$ e Outros, com 10 espécies (06,33\%). Na categoria Outros foram reunidas as espécies citadas para sombra (04 espécies), curtume (01 espécie), reservatório de água, usado para armazenar água nas idas ao campo (01 espécie), repelente / inseticida (02 espécies) e adubo (01 espécie). As espécies citadas e suas respectivas categorias podem ser observadas na Tabela 1.

Tabela 1. Espécies citadas pelos informantes residentes no Assentamento Tabuleiro Grande, Apodi (RN), com respectivas categorias de uso. Convenções: (a) madeira, (b) medicina/higiene, (c) apicultura, (d) lenha, (e) veterinária popular, (f) forragem, (g) alimentação humana, (h) outro, (NI) não-identificado.

\begin{tabular}{|c|c|c|}
\hline Nome científico & Nome popular & Usos \\
\hline \multicolumn{3}{|l|}{ Anacardiaceae } \\
\hline Mangifera sp. & Manga & g \\
\hline Myracrodruon urundeuva Allemão & Aroeira & $\mathrm{a}, \mathrm{b}, \mathrm{c}, \mathrm{d}, \mathrm{e}, \mathrm{f}$ \\
\hline Spondias mombin $\mathrm{L}$. & Cajá & $\mathrm{c}, \mathrm{g}$ \\
\hline Spondias purpuea $\mathrm{L}$. & Siriguela & $\mathrm{c}, \mathrm{g}$ \\
\hline Spondias sp. & Cajarana & $\mathrm{c}, \mathrm{g}$ \\
\hline \multicolumn{3}{|l|}{ Apocynaceae } \\
\hline Aspidosperma pyrifolium Mart. & Pereiro & $\mathrm{a}, \mathrm{d}, \mathrm{h}$ \\
\hline \multicolumn{3}{|l|}{ Arecaceae } \\
\hline \multirow{2}{*}{\multicolumn{3}{|c|}{ Bignoniaceae }} \\
\hline & & \\
\hline Handroanthus heptaphyllus (Vell.) Mattos & Pau-d'arco-roxo & $\mathrm{c}$ \\
\hline Handroanthus sp. & Pau-d'arco-branco & $\mathrm{a}, \mathrm{b}, \mathrm{c}$ \\
\hline Tabebuia aurea (Silva Manso) Benth. \& Hook. f ex S. Moore & Craibeira & $\mathrm{a}, \mathrm{f}$ \\
\hline \multicolumn{3}{|l|}{ Bixaceae } \\
\hline Cochlosperma vitifolium (Willd.) Spreng & Pacotê & $\mathrm{b}, \mathrm{e}$ \\
\hline \multicolumn{3}{|l|}{ Boraginaceae } \\
\hline Cordia oncocalix Allemão & Pau-branco & $\mathrm{a}, \mathrm{c}$ \\
\hline Cordia trichotoma (Vell.) Arrab. ex. Steud. & Frei-jorge & $\mathrm{a}, \mathrm{c}$ \\
\hline \multicolumn{3}{|l|}{ Burseraceae } \\
\hline Commiphora leptophloeos (Mart.) J. B. Gillett & Imburana & $a, b, c, d, f$ \\
\hline \multicolumn{3}{|l|}{ Cactaceae } \\
\hline Cereus jamacaru DC & Cardeiro & $\mathrm{f}, \mathrm{g}$ \\
\hline \multicolumn{3}{|l|}{ Chrysobalanaceae } \\
\hline Licania rigida Benth. & Oiticica & $\mathrm{b}, \mathrm{c}, \mathrm{d}, \mathrm{h}$ \\
\hline \multicolumn{3}{|l|}{ Combretaceae } \\
\hline Combretum leprosum Mart. & Mofumbo & $a, b, c, d, f, h$ \\
\hline \multicolumn{3}{|l|}{ Euphorbiaceae } \\
\hline Cnidoscolus phyllacanthus ( Müll. Arg.) Pax \& L. Hoffm. & Faveleira & $\mathrm{f}, \mathrm{h}$ \\
\hline Croton sonderianus Müll. Arg. & Marmeleiro & $a, b, c, d, e$ \\
\hline Manihot carthagenensis subsp. glaziovii Müll. Arg. & Maniçoba & $\mathrm{c}, \mathrm{f}$ \\
\hline \multicolumn{3}{|l|}{ Fabaceae - Caesalpinioidae } \\
\hline Bauhinia cheilantha (Bong.) Steud. & Mororó & $a, b, c, e, f, g$ \\
\hline Libidibia ferrea (Mart. ex Tul.) L.P. Queiroz. & Jucá & $b, c, d, e, f$ \\
\hline Caesalpinia pyramidalis Tul. & Catingueira & $\mathrm{a}, \mathrm{b}, \mathrm{c}, \mathrm{d}, \mathrm{e}, \mathrm{f}, \mathrm{h}$ \\
\hline Tamarindus indica $\mathrm{L}$. & Tamarindo & $\mathrm{g}$ \\
\hline \multicolumn{3}{|l|}{ Fabaceae - Faboideae } \\
\hline Amburana cearensis (Allemão) A. C. Sm. & Cumaru & $a, b, c, h$ \\
\hline \multicolumn{3}{|l|}{ Fabaceae - Mimosoidae } \\
\hline Anadenanthera colubrina (Vell.) Brenan & Angico-branco & $a, b, d$ \\
\hline Anadenanthera macrocarpa (Benth) Brenan & Angico-preto & $\mathrm{a}, \mathrm{c}, \mathrm{d}, \mathrm{f}$ \\
\hline Leucaenia leucocephala (Lam.) de Wit & Leocena & $b, f$ \\
\hline Mimosa opthalmocentra Mart. ex Benth. & Jurema-de-imbira & $\mathrm{a}, \mathrm{c}, \mathrm{d}, \mathrm{f}$ \\
\hline Mimosa tenuiflora (Willd.) Poir. & Jurema-preta & $a, b, c, f$ \\
\hline Piptadenia stipulacea (Benth.) Ducke & Jurema-branca & $\mathrm{a}, \mathrm{c}, \mathrm{f}$ \\
\hline Prosopis juliflora $(\mathrm{Sw}) \mathrm{DC}$ & Algaroba & $\mathrm{d}, \mathrm{f}$ \\
\hline Senegalia $s p .1$ & Espinheiro-da-semente-preta & $c, f$ \\
\hline Senegalia sp. 2 & Espinheiro-da-semente-vermelha & $\mathrm{c}, \mathrm{f}$ \\
\hline \multicolumn{3}{|l|}{ Fabaceae - Papilonoidae } \\
\hline Luetzelburgia auriculata (Allemão) Ducke & Pau-mocó & $\mathrm{c}$ \\
\hline \multicolumn{3}{|l|}{ Lythraceae } \\
\hline Punica granatum $\mathrm{L}$. & Romã & $\mathrm{b}$ \\
\hline \multicolumn{3}{|l|}{ Malpighiaceae } \\
\hline Malpighia emarginata DC & Acerola & $\mathrm{g}$ \\
\hline \multicolumn{3}{|l|}{ Malvaceae } \\
\hline Pseudobombax marginatum (A. St. - Hill) A. Robyns & Embiratanha & $\mathrm{b}, \mathrm{e}$ \\
\hline Meliaceae & & \\
\hline Azadirachta indica A. Juss. & $\mathrm{Nim}$ & $\mathrm{e}, \mathrm{h}$ \\
\hline
\end{tabular}




\begin{tabular}{|c|c|c|}
\hline Nome científico & Nome popular & Usos \\
\hline \multicolumn{3}{|l|}{ Moraceae } \\
\hline Artocarpus heterophyllus Lam. & Jaca & $\mathrm{g}$ \\
\hline \multicolumn{3}{|l|}{ Myrtaceae } \\
\hline Psidium guajava $\mathrm{L}$. & Goiaba & $\mathrm{b}, \mathrm{g}$ \\
\hline \multicolumn{3}{|l|}{ Olacaceae } \\
\hline Ximenia americana $\mathrm{L}$. & Ameixa & $\mathrm{b}, \mathrm{e}, \mathrm{f}, \mathrm{g}$ \\
\hline \multicolumn{3}{|l|}{ Rhamnaceae } \\
\hline Ziziphus joazeiro Mart & Juazeiro & $\mathrm{b}, \mathrm{c}, \mathrm{f}, \mathrm{h}$ \\
\hline \multicolumn{3}{|l|}{ Rubiaceae } \\
\hline Genipa americana L. & Jenipapo & $\mathrm{b}, \mathrm{c}$ \\
\hline \multicolumn{3}{|l|}{ Rutaceae } \\
\hline Citrus sp. 1 & Laranja & $\mathrm{g}$ \\
\hline Citrus sp. 2 & Limão & $\mathrm{b}, \mathrm{g}$ \\
\hline \multicolumn{3}{|l|}{ Sapotaceae } \\
\hline Sideroxylon obtusifolium (Roem \& Schult.) T. D. Penn & Quixabeira-branca & $\mathrm{b}, \mathrm{d}, \mathrm{f}, \mathrm{g}$ \\
\hline Sideroxylon sp. & Quixabeira-preta & $\mathrm{c}, \mathrm{d}, \mathrm{f}, \mathrm{g}$ \\
\hline NI & Angilim & $\mathrm{a}, \mathrm{c}, \mathrm{d}$ \\
\hline NI & Cabelo-de-nego & B \\
\hline NI & Cedro & $b, f$ \\
\hline NI & Coité & $\mathrm{c}, \mathrm{h}$ \\
\hline NI & Feijão-bravo & $c, f$ \\
\hline NI & Imbú & $\mathrm{c}, \mathrm{g}$ \\
\hline NI & João-mole & $\mathrm{b}, \mathrm{e}$ \\
\hline NI & Jurubeba-com-espinho & $c, f$ \\
\hline NI & Jurubeba-sem-espinho & $c, f$ \\
\hline
\end{tabular}

Em outros levantamentos etnobotânicos como os realizados por Botrel (2006) e Miranda;e Hanazaki (2008), a categoria Medicina se destaca, com maior número de espécies citadas, o que não ocorre no presente levantamento.

A categoria Lenha se destacou no que diz respeito a número de informantes. Neste caso, 21 entrevistados citaram espécies para este fim. Também observa-se destaque para Medicina/Higiene (20 informantes), Madeira (19 informantes), Forragem (16 informantes), Outros (13 informantes), Apicultura (12 informantes), Veterinária popular (10 informantes) e Alimentação humana (10 informantes). Percebe-se que um grande número de etnoespécies na categoria não implica num maior conhecimento por parte dos entrevistados, pois o conhecimento está retido a uma parcela dos informantes, sendo como exemplo a categoria Apicultura, que ocorreu o maior número de citações (33 espécies), mas com a contribuição de apenas 12 informantes (Figura 4). Essa retenção do conhecimento é responsável pelo destaque da categoria Apicultura, divergindo de outros levantamentos etnobotânicos, onde a categoria Medicina recebeu maior número de espécies úteis (ALMEIDA, 2011; LUCENA et al, 2012; ROQUE; LOIOLA, 2013). O índice de equabilidade de Pielou para o assentamento $(0,39)$ foi considerado baixo, mostrando que o conhecimento realmente está concentrado em uma parcela da população. O mesmo é inferior ao encontrado por Cunha e Bortolotto (2011) no Assentamento Monjolinho, município de Anastácio, MS $(0,94)$, por Ferraz et al (2006) em Riacho do Navio, Floresta, PE $(0,76)$, ambos na zona rurais, e por Santos et al. (2016) em uma comunidade indígena em Altamira, PA.
Figura 4. Comparação entre o número de espécies e o número de informantes por categoria de uso no Projeto de Assentamento Tabuleiro Grande, Apodi, Rio Grande do Norte

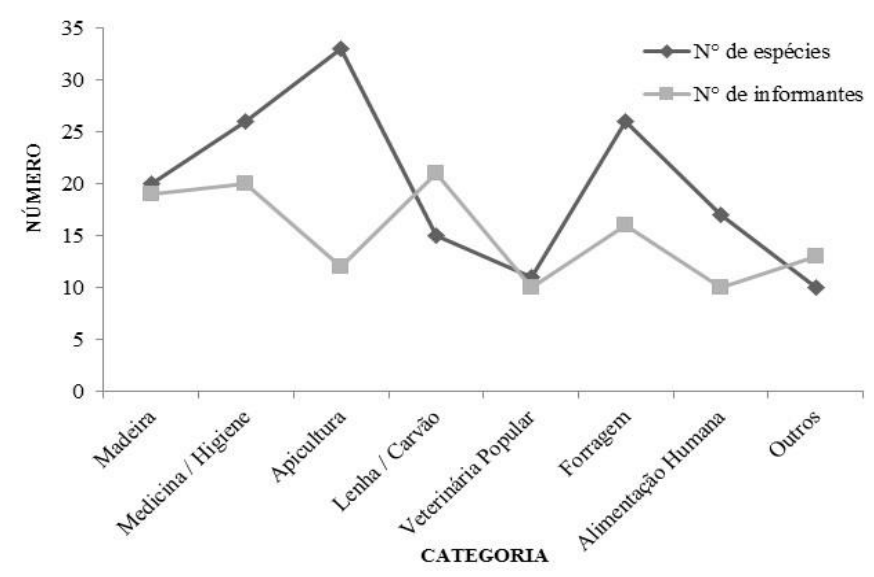

As espécies com maior valor de uso (VU) foram: Myracrodruon urundeuva Allemão ( $\mathrm{VU}=2,333$ ), citada nas categorias Madeira, Medicina/Higiene, Apicultura, Lenha, Veterinária Popular e Forragem; Caesalpinia pyramidalis Tul. $(\mathrm{VU}=1,381)$, citada nas categorias Madeira, Medicina/Higiene, Apicultura, Lenha, Veterinária Popular, Forragem e Outros; Ziziphus joazeiro Mart (VU = 1,048), para Medicina/Higiene, Apicultura, Forragem e Outros; e Aspidosperma pyrifolium Mart ( $\mathrm{VU}=1,000)$, citada para Madeira, Lenha e Outros (Tabela 2). A utilização da espécie pela comunidade é diretamente proporcional ao Valor de uso. Apesar disso, a maioria das citações dessas espécies veio acompanhada da afirmação em relação a facilidade de encontrá-las. 
Tabela 2. Lista de espécies citadas pelos informantes residentes no Assentamento Tabuleiro Grande, Apodi (RN), com respectivo Valor de Uso (VU).

\begin{tabular}{|c|c|c|}
\hline 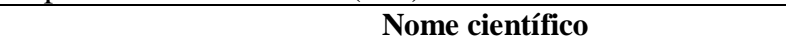 & Nome popular & VU \\
\hline Amburana cearensis (Allemão) A. C. Sm. & Cumaru & 0,714 \\
\hline Anadenanthera colubrina (Vell.) Brenan & Angico-branco & 0,238 \\
\hline Anadenanthera macrocarpa (Benth) Brenan & Angico-preto & 0,190 \\
\hline Artocarpus heterophyllus Lam. & Jaca & 0,048 \\
\hline Aspidosperma pyrifolium Mart. & Pereiro & 1,000 \\
\hline Azadirachta indica A. Juss. & Nim & 0,143 \\
\hline Bauhinia cheilantha (Bong.) Steud. & Mororó & 0,762 \\
\hline Libidibia ferrea (Mart. ex Tul.) L.P. Queiroz & Jucá & 0,857 \\
\hline Caesalpinia pyramidalis Tul. & Catingueira & 1,381 \\
\hline Cereus jamacaru DC & Cardeiro & 0,095 \\
\hline Citrus sp. 1 & Laranja & 0,048 \\
\hline Citrus sp. 2 & Limão & 0,190 \\
\hline Cnidoscolus phyllacanthus ( Müll. Arg.) Pax \& L. Hoffm. & Faveleira & 0,095 \\
\hline Cochlosperma vitifolium (Willd.) Spreng & Pacotê & 0,095 \\
\hline Cocus nucifera $\mathrm{L}$. & Coqueiro & 0,048 \\
\hline Combretum leprosum Mart. & Mofumbo & 0,667 \\
\hline Commiphora leptophloeos (Mart.) J. B. Gillett & Imburana & 0,476 \\
\hline Cordia oncocalix Allemão & Pau-branco & 0,143 \\
\hline Cordia trichotoma (Vell.) Arrab. ex. Steud. & Frei-jorge & 0,095 \\
\hline Croton sonderianus Müll. Arg. & Marmeleiro & 0,571 \\
\hline Genipa americana L. & Jenipapo & 0,095 \\
\hline Handroanthus heptaphyllus (Vell.) Mattos & Pau-d'arco-roxo & 0,048 \\
\hline Handroanthus sp. & Pau-d'arco-branco & 0,143 \\
\hline Leucaenia leucocephala (Lam.) de Wit & Leocena & 0,238 \\
\hline Licania rigida Benth. & Oiticica & 0,190 \\
\hline Luetzelburgia auriculata (Allemão) Ducke & Pau-mocó & 0,048 \\
\hline Malpighia emarginata DC & Acerola & 0,143 \\
\hline Mangifera sp. & Manga & 0,238 \\
\hline Manihot carthagenensis subsp. glaziovii Müll. Arg. & Maniçoba & 0,095 \\
\hline Mimosa opthalmocentra Mart. ex Benth. & Jurema-de-imbira & 0,571 \\
\hline Mimosa tenuiflora (Willd.) Poir. & Jurema-preta & 0,476 \\
\hline Myracrodruon urundeuva Allemão & Aroeira & 2,333 \\
\hline Piptadenia stipulacea (Benth.) Ducke & Jurema-branca & 0,286 \\
\hline Prosopis juliflora (Sw) DC & Algaroba & 0,190 \\
\hline Pseudobombax marginatum (A. St. - Hill) A. Robyns & Embiratanha & 0,286 \\
\hline Psidium guajava $\mathrm{L}$. & Goiaba & 0,190 \\
\hline Punica granatum $\mathrm{L}$. & Romã & 0,048 \\
\hline Senegalia sp. 1 & Espinheiro-da-semente-preta & 0,095 \\
\hline Senegalia sp. 2 & Espinheiro-da-semente-vermelha & 0,095 \\
\hline Sideroxylon obtusifolium (Roem \& Schult.) T. D. Penn & Quixabeira-branca & 0,476 \\
\hline Sideroxylon sp. & Quixabeira-preta & 0,286 \\
\hline Spondias mombin $\mathrm{L}$. & Cajá & 0,095 \\
\hline Spondias purpuea $\mathrm{L}$. & Siriguela & 0,333 \\
\hline Spondias sp. & Cajarana & 0,381 \\
\hline Tabebuia aurea (Silva Manso) Benth. \& Hook. f ex S. Moore & Craibeira & 0,095 \\
\hline Tamarindus indica $\mathrm{L}$. & Tamarindo & 0,048 \\
\hline Ximenia americana $\mathrm{L}$. & Ameixa & 0,714 \\
\hline Ziziphus joazeiro Mart & Juazeiro & 1,048 \\
\hline $\mathrm{NI}$ & Angilim & 0,143 \\
\hline NI & Cabelo-de-nego & 0,048 \\
\hline NI & Cedro & 0,095 \\
\hline NI & Coité & 0,095 \\
\hline NI & Feijão-bravo & 0,095 \\
\hline NI & Imbú & 0,095 \\
\hline NI & João-mole & 0,143 \\
\hline NI & Jurubeba-com-espinho & 0,095 \\
\hline NI & Jurubeba-sem-espinho & 0,095 \\
\hline
\end{tabular}

É importante ressaltar que apesar de citada, a espécie $M$. urundeuva Allemão, de acordo com os informantes, não é utilizada para fins madeireiros e como combustível, pois é "madeira de lei". Isso indica o conhecimento por parte da comunidade a respeito da legislação ambiental. Esse fato é importante no tocante a preservação da espécie em questão.

$\mathrm{Na}$ categoria Medicina/Higiene foram citadas espécies para o tratamento de doenças relacionadas ao sistema reprodutor, sistema respiratório, sistema digestivo, sistema urinário, sistema circulatório, inflamações em geral, diabetes, ferimentos, dores na coluna e outros (Figura 5).

Destacaram-se Myracrodruon urundeuva Allemão, com 15 citações, Libidibia ferrea (Mart. ex Tul.) L.P. Queiroz, Ziziphus joazeiro Mart, Amburana cearensis (Allemão) A. C. Sm. e Ximenia americana L., com 07 citações cada. Das 26 espécies da categoria, 02 foram citadas para higiene, sendo 
Ziziphus joazeiro Mart usada para lavar o cabelo e escovar os dentes e Licania rigida Benth., para a fabricação de sabão.

Figura 5. Distribuição dos usos das espécies medicinais citadas pelos informantes residentes no Assentamento Tabuleiro Grande, Apodi, Rio Grande do Norte

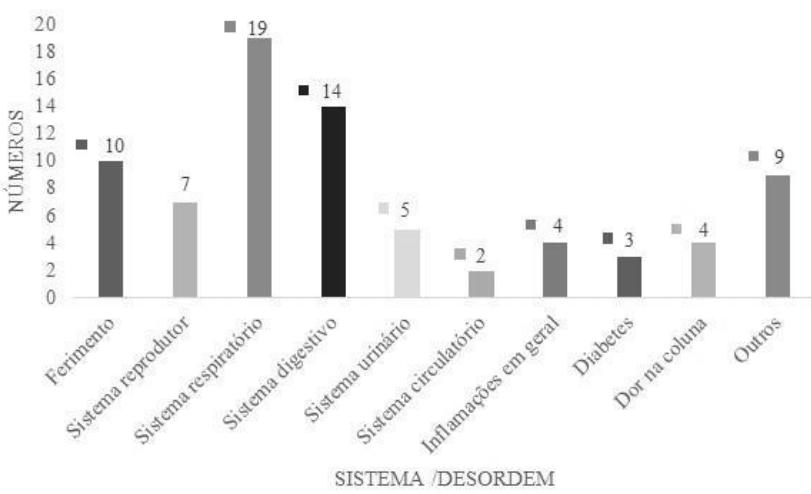

Na tabela 3 detalha-se as formas de uso e partes que são utilizadas das espécies medicinais. Observa-se que o uso da casca do tronco foi o mais citado $(79,00 \%)$, seguido de fruto/semente $(09,00 \%)$, flor $(06,00 \%)$, folha $(04,00 \%)$ e exsudações $(02,00 \%)$. Essas informações são muito importante considerando que a retirada da casca do tronco de forma descuidada pode levar ao anelamento do indivíduo arbóreo. $\mathrm{O}$ anelamento consiste na retirada de câmbio numa faixa ao redor do caule, o que interrompe a circulação da seiva elaborada e leva a morte da planta. No entanto, cabe salientar que a tabela se refere a "conhecimento" e não "uso" das espécies arbóreas, indicando que sua preservação, pelo menos quanto ao uso medicinal, está assegurada.

Quanto ao preparo de tratamentos fitoterápicos, o molho em água fria foi o mais citado (56 citações), seguido do melador (29 citações), cozimento/chá (24 citações), maceração (09 citações) e suco (01 citação). Foi ainda citada a utilização natural de partes das plantas.

Tabela 3. Usos atribuídos as espécies medicinais citadas pelos informantes residentes no Assentamento Tabuleiro Grande, Apodi, Rio Grande do Norte.

\begin{tabular}{lcc}
\hline \multicolumn{1}{c}{ Nome científico } & Nome popular & Parte usada \\
\hline $\begin{array}{l}\text { Amburana cearensis (Allemão) A. C. Sm. } \\
\text { Anadenanthera colubrina (Vell.) Brenan }\end{array}$ & $\begin{array}{c}\text { Cumaru } \\
\text { Angico-branco }\end{array}$ & $\begin{array}{c}\text { Casca do tronco } \\
\text { Casca do tronco; flor }\end{array}$ \\
Bauhinia cheilantha (Bong.) Steud. & Mororó & Casca do tronco; folhas
\end{tabular}

Jucá

Casca do tronco; fruto

\section{Libidibia ferrea (Mart. ex Tul.) L.P. Queiroz}

Catingueira

Casca do tronco; flor

$\begin{array}{cc}\text { Limão } & \text { Fruto } \\ \text { Pacotê } & \text { Casca do tronco }\end{array}$

Cochlosperma vitifolium (Willd.) Spreng

Pacotê

Casca do tronco; exsudação

Commiphora leptophloeos (Mart.) J. B. Gillett

Imburana

Marmeleiro

Jenipapo

Genipa americana $\mathrm{L}$.

Handroanthus sp.

Leucaenia leucocephala (Lam.) de Wit

Mimosa tenuiflora (Willd.) Poir.

Myracrodruon urundeuva Allemão

Pseudobombax marginatum (A. St. - Hill) A. Robyns

Embiratanha

Casca do tronco

Goiaba
Casca do tronco

Fruto

Casca do tronco

Semente

Casca do tronco

Casca do tronco
Aroeira
Preparo e Indicação

Melador para gripe. Molho ou cozida para sinusite e resfriado.

Melador, para gripe.

Chá da casca para problemas nos rins. Melador da casca para gripe. Molho da casca para cicatrizar e baixar o colesterol. Chá das folhas para problemas nos rins e para baixar o colesterol.

Fruto macerado de molho para dor na coluna, problemas de visão, inflamações e gripe. Casca do tronco cozida para cicatrizar.

Melador para gripe, cansaço e resfriado. Molho da casca para dor de barriga.

Suco sem açúcar para enjoo e mal-estar.

Molho, para azia, gastrite e úlcera. Casca de molho para cicatrizar.

Exsudação do tronco para dor de dente. Casca cozida para cicatrização e inflamações.

Raspa de molho para problemas intestinais. Chá da raspa para má digestão. Raspa seca e macerada para cicatrização e dor de dente.

Colocado sobre contusões.

Molho para problemas nos rins e diabetes.

Macerada, para osteoporose e câncer de pele.

Melador para gripe. Cozimento ou molho para cicatrizar.

Para cicatrização, de molho, cozida ou macerada. Cozida, serve ainda para problemas no útero. Usada para fazer melador para gripe e inflamações.

Molho para câncer de mama e de próstata, problemas nos rins, gastrite, dor na coluna e é anticoncepcional.

Chá da última folha do galho para diarreia. 


\begin{tabular}{|c|c|c|c|}
\hline Nome científico & Nome popular & Parte usada & Preparo e Indicação \\
\hline Punica granatum $\mathrm{L}$. & Romã & Casca do fruto; sementes & $\begin{array}{c}\text { Molho para inflamação na } \\
\text { garganta. }\end{array}$ \\
\hline $\begin{array}{l}\text { Sideroxylon obtusifolium (Roem \& Schult.) T. } \\
\text { D. Penn }\end{array}$ & Quixabeira-branca & Casca do tronco & $\begin{array}{c}\text { Molho, para dor na coluna, } \\
\text { problema nos rins, câncer e } \\
\text { gastrite. Melador para dor na } \\
\text { coluna, gripe e gastrite. Macerada } \\
\text { serve para cicatrizar. }\end{array}$ \\
\hline Ximenia americana $\mathrm{L}$. & Ameixa & Casca do tronco & $\begin{array}{c}\text { Para cicatrização, de molho, } \\
\text { cozida ou macerada. A água } \\
\text { ingerida serve para todo tipo de } \\
\text { enfermidade. }\end{array}$ \\
\hline Ziziphus joazeiro Mart. & Juazeiro & Casca do tronco & $\begin{array}{c}\text { Raspa de molho para cicatrizar. } \\
\text { Melador para asma. }\end{array}$ \\
\hline NI & Cabelo-de-nego & Casca do tronco & $\begin{array}{l}\text { Molho para dor na coluna e câncer } \\
\text { de próstata. }\end{array}$ \\
\hline NI & Cedro & Sementes & Chá para asma. \\
\hline NI & João-mole & Casca do tronco & Molho, para próstata. \\
\hline
\end{tabular}

$\mathrm{Na}$ categoria Veterinária popular foram citadas plantas para cicatrização, problemas no parto, cegueira, inseticida, desordens intestinais, vermífugo e picada de cobra (Figura 6). Destacaram-se Myracrodruon urundeuva Allemão e Libidibia ferrea (Mart. ex Tul.) L.P. Queiroz, cada um com 04 citações. Na tabela 4 detalha-se os usos e partes utilizadas das espécies veterinárias, sendo que assim como na categoria Medicina/Higiene, na Veterinária popular a casca do tronco foi a parte mais citada, com 08 citações, seguida por folhas e frutos, cada uma com 02 citações.

Sobre o preparo dos tratamentos fitoterápicos veterinários, o molho em água fria foi o mais citado, com 08 citações, seguido do cozimento (03 citações), e preparo com sal e batata de purga (01 citação).
Figura 6. Distribuição dos usos das espécies citadas na categoria Veterinária no Assentamento Tabuleiro Grande, Apodi, Rio Grande do Norte

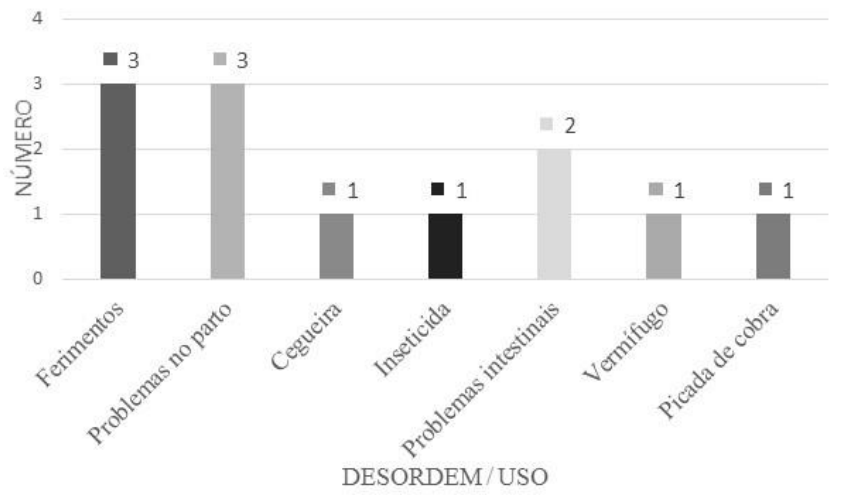

Tabela 4. Usos atribuídos as espécies citadas na categoria Veterinária no Assentamento Tabuleiro Grande, Apodi, Rio Grande do Norte

\begin{tabular}{|c|c|c|c|}
\hline Nome científico & Nome popular & Parte usada & Preparo e indicação \\
\hline Azadirachta indica A. Juss. & Nim & Folhas & Molho para matar pulgas e carrapatos. \\
\hline $\begin{array}{l}\text { Bauhinia cheilantha (Bong.) } \\
\text { Steud. }\end{array}$ & Mororó & Casca do tronco & Molho para cicatrizar. \\
\hline $\begin{array}{l}\text { Libidibia ferrea (Mart. ex Tul.) } \\
\text { L.P. Queiroz. }\end{array}$ & Jucá & Fruto & Macerado e de molho para cegueira. \\
\hline Caesalpinia pyramidalis Tul. & Catingueira & Folhas & Chá para dor de barriga. \\
\hline Citrus sp. 2 & Limão & Fruto & Cortado, com sal e batata de purga é vermífugo. \\
\hline $\begin{array}{l}\text { Cochlosperma vitifolium (Willd.) } \\
\text { Spreng }\end{array}$ & Pacotê & Casca do tronco & $\begin{array}{c}\text { Raspa de molho para animais doentes depois do } \\
\text { parto. }\end{array}$ \\
\hline Croton sonderianus Müll. Arg. & Marmeleiro & Casca do tronco & Molho para problemas intestinais. \\
\hline $\begin{array}{l}\text { Myracrodruon urundeuva } \\
\text { Allemão }\end{array}$ & Aroeira & Casca do tronco & Cozimento para cicatrização. \\
\hline NI & João-mole & Casca do tronco & $\begin{array}{c}\text { Molho para quando o animal está segurando o } \\
\text { parto. }\end{array}$ \\
\hline $\begin{array}{l}\text { Pseudobombax marginatum (A. } \\
\text { St. - Hill) A. Robyns }\end{array}$ & Embiratanha & Casa do tronco & Molho para picada de cobra. \\
\hline $\begin{array}{l}\text { Pseudobombax marginatum (A. } \\
\text { St. - Hill) A. Robyns }\end{array}$ & Embiratanha & Casca do tronco & $\begin{array}{c}\text { Molho para quando o animal está segurando o } \\
\text { parto. }\end{array}$ \\
\hline Ximenia americana $\mathrm{L}$. & Ameixa & Casca do tronco & Cozimento para cicatrização. \\
\hline
\end{tabular}

Quando questionados sobre que espécies evitavam, a espécie Aspidosperma pyrifolium Mart. (Pereiro) foi citada por 11 vezes, devido a alta produção de fumaça. No entanto, mesmo conscientes deste fato, alguns informantes afirmaram que o Pereiro pode ser usado como combustível. Na coleta da lenha não há conflitos, pois ela é extraída dos lotes pertencentes aos moradores.

Nas outras categorias, destacaram-se Myracrodruon urundeuva Allemão (07 citações) como espécie apícola, segundo os informantes produzindo o melhor mel dentre 
todas as árvores; Ziziphus joazeiro Mart (10 citações) como espécie forrageira; Aspidosperma pyrifolium Mart. (16 citações) na categoria Madeira, na confecção de móveis; e Spondias sp. (07 citações) na categoria Alimentação humana, consumida ao natural ou em forma de suco.

Sobre a fonte do conhecimento etnobotânico (Figura 7), a maioria declarou ter adquirido dos pais $(54,00 \%)$, e $08,00 \%$ afirmaram ser autodidata, estando esse conhecimento certamente relacionado à outra forma de obtenção, pois o uso da vegetação sem conhecimento prévio poderia levar a acidentes e, no entanto, não existem relatos disso.

Figura 7. Distribuição percentual das formas de obtenção do conhecimento etnobotânico no Projeto de Assentamento Tabuleiro Grande, Apodi, Rio Grande do Norte

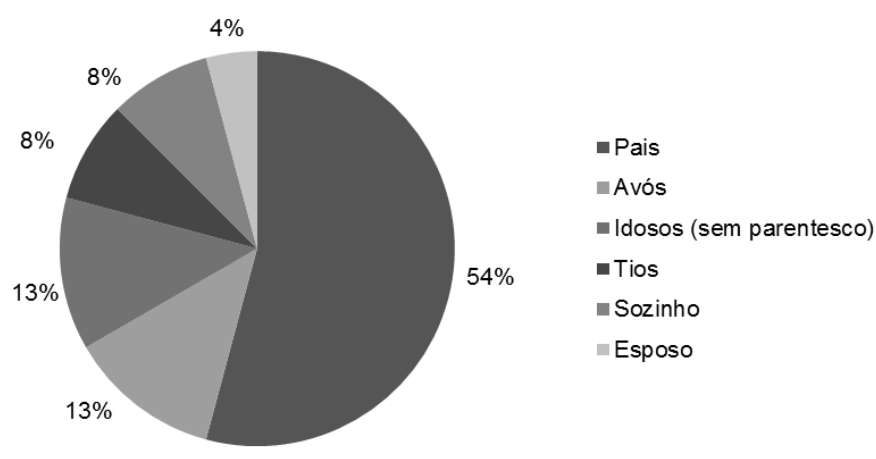

Referindo-se ao repasse do conhecimento a outras pessoas, 48,00\% afirmaram não ensinar sobre a utilização das plantas, o que pode gerar a perda dessas informações em longo prazo.

\section{CONCLUSÕES}

Um grande número de espécies arbóreas tem potencial de uso principalmente para apicultura, medicina e forragem na área de estudo. Porém, apesar de demonstrar conhecimento sobre formas de uso e utilidades, a comunidade estudada sugere que nem todas as espécies citadas são utilizadas de fato.

O conhecimento local sobre uso de espécies arbóreas nativas não é distribuído uniformemente entre os informantes. Aqueles que contém a maior parcela desse conhecimento não tem o hábito de repassá-lo, tendendo a torná-lo cada vez mais escasso.

\section{REFERÊNCIAS}

ALBUQUERQUE U. P.; ANDRADE L. H. C. Conhecimento botânico tradicional e conservação em uma área de caatinga no estado de Pernambuco. Acta Botânica Brasilica, Belo Horizonte, v. 16, n. 3, p. 273-285, 2001.

ALBUQUERQUE U. P.; HANAZAKI N. As pesquisas etnodirigidas na descoberta de novos fármacos de interesse médico e farmacêutico: fragilidades e perspectivas. Revista Brasileira de Farmacognosia, Curitiba, v. 16, p. 678-689, 2006.
ALENCAR E.; GOMES M. A. O. Metodologia de pesquisa social e diagnóstico rápido participativo. 1.ed. Lavras: Editora UFLA/FAEPE, 1988, v.1. 212p.

ALMEIDA V. S. Uso, manejo e estrutura da vegetação da caatinga por duas comunidades quilombolas do município de Jeremoabo, Bahia, Brasil. UEFS. 2011. 161f. Tese (Doutorado em Botânica) Universidade Estadual de Feira de Santana. 2011.

ALVES, G. S. P.; POVH, J. A. Estudo etnobotânico de plantas medicinais na comunidade de Santa Rita, Ituiutaba MG. Biotemas, Florianópolis, v. 26, n.3, p. 231-242. 2013.

BEGOSSI A. Use for ecological methods in ethnobotany: diversity índices. Economic Botany, London, v.50, n.3, p. 280-289, 1996.

BOTREL, R. T.; RODRIGUES, L. A.; GOMES, L. J.; CARVALHO, D. A.; FONTES, M. A. L. Uso da vegetação nativa pela população local no município de Ingaí, MG, Brasil. Acta Botanica Brasílica, Belo Horizonte, v. 20, n.1, p 143-156, 2006.

BRASIL. Ministério das Minas e Energia. Projeto cadastro de fontes de abastecimento por água subterrânea. Diagnóstico do município de Livramento. Recife: CPRM, 2005. Disponível: <http://rigeo.cprm.gov.br/xmlui/bitstream/handle/doc/16238/r el_apodi.pdf?sequence=1> Acessado em: 20 de Julho de 2016.

CUNHA, S. A. da; BORTOLOTTO, I. M. Etnobotânica de Plantas Medicinais no Assentamento Monjolinho, município de Anastácio, Mato Grosso do Sul, Brasil. Feira de Santana. Acta Botanica Brasílica, Belo Horizonte, v. 25, n. 3, p. 685698. 2011.

FERRAZ J. S. F., ALBUQUERQUE U. P.; MEUNIER I. M. J. Valor de uso e estrutura da vegetação lenhosa às margens do riacho do Navio, Floresta, Pernambuco, Brasil. Acta Botanica Brasilica, Belo Horizonte, v.20, n.1, p. 125-134, 2006.

FERRAZ J. S. F., MEUNIER I. M. J.; ALBUQUERQUE U. P. Conhecimento sobre espécies lenhosas úteis da mata ciliar do Riacho do Navio, Floresta, Pernambuco. Zonas Áridas, Lima, v.9, p. 27-39, 2005.

KENT, M. E.; COKER, P. Vegetation description and analysis. Reino Unido: Belhaven, 1992. 363 p.

LUCENA R. F. P, SOARES T. C, VASCONCELOS NETO C. F. A., CARVALHO T. K. N., LUCENA C. M.; ALVES R. R. N. Uso de recursos vegetais da caatinga em uma comunidade rural no curimataú paraibano (Nordeste do Brasil). Polibotánica, Colonia Santo Tomás, v.34, p. 217-238, 2012.

MAIA G. N. Caatinga: árvores e arbustos e suas utilidades. 2. ed. Fortaleza: editora Printcolor. 2012, 413 p. il. 
MASCARENHAS J. C., BELTRÃO B. A., SOUZA JÚNIOR L. C., PIRES S. T. M., ROCHA D.; CARVALHO V. G. D. (org.). Diagnóstico do município de Apodi, estado do Rio Grande do Norte. Recife: CPRM/PRODEEM. 2005.

MIRANDA, T. M.; HANAZAKI, N. Conhecimento e uso de recursos vegetais de restinga por comunidades das ilhas do Cardoso (SP) e de Santa Catarina (SC), Brasil. Acta Botanica Brasílica, Belo Horizonte, v 22, n.1, p. 203-215, 2008.

PHILLIPS O.; GENTRY, A. H. The useful plants of Tambopata, Peru. I. Statistical hypotheses with a new quantitative technique. Economic Botany, London, v.47, n.1, p. 33-43. 1993.

ROQUE A. A., LOIOLA, M. I. B. Potencial de uso dos recursos vegetais em uma comunidade rural no semiárido potiguar. Revista Caatinga, Mossoró, v. 26, n.4, p. 88-98, 2013.

SANTANA JÚNIOR H. E. Zoneamento agroecológico do município de Apodi/RN. 2010. 121f. Dissertação (Mestrado em Desenvolvimento e Meio Ambiente). Universidade Federal do Rio Grande do Norte, Natal. 2010.

SANTOS, J. X. dos; REIS, A. R. S.; MATOS, S. A. de; LEÃO, F. M.; CARVALHO, J. C. de. Caracterização etnobotânica de essências florestais com fins medicinais utilizadas pela Etnia Xipaya, no município de Altamira-PA. Biota Amazônia, Macapá, v. 6, n. 2, p. 1-8, 2016.

SILVA, N. C. B.; REGIS, A. C. D.; ALMEIDA, M. Z. Estudo Etnobotânico em Comunidades Remanescentes de Quilombo em Rio de Contas - Chapada Diamantina - Bahia. Revista Fitos, Rio de Janeiro, v. 7, n. 2, 2012.

SOUZA M. J. N. A problemática ambiental: cenários para o bioma caatinga no Nordeste do Brasil. In: SILVA J.B., LIMA L.C., DANTAS E.W.C. (org.). Panorama da geografia brasileira. São Paulo: Annablume, 2006, v. 2, p. 119-133. 